\title{
Circuit Implementation and Synchronization Control of Chaotic Horizontal Platform Systems by Wireless Sensors
}

\author{
Meei-Ling Hung ${ }^{1}$ and Her-Terng Yau ${ }^{2}$ \\ ${ }^{1}$ Department of Electrical Engineering, Far East University, Tainan 74448, Taiwan \\ ${ }^{2}$ Department of Electrical Engineering, National Chin-Yi University of Technology, Taichung 41170, Taiwan \\ Correspondence should be addressed to Her-Terng Yau; pan1012@ms52.hinet.net
}

Received 19 February 2013; Accepted 21 March 2013

Academic Editor: Jui-Sheng Lin

Copyright (c) 2013 M.-L. Hung and H.-T. Yau. This is an open access article distributed under the Creative Commons Attribution License, which permits unrestricted use, distribution, and reproduction in any medium, provided the original work is properly cited.

\begin{abstract}
Horizontal platform system (HPS) produces a nonlinear behavior from precision machinery systems. This mechanical system is implemented mainly in offshore areas or earthquake engineering. However, elucidating or controlling this non-linear behavior of mechanical systems is extremely difficult and time consuming. Therefore, in addition to developing an electronic circuit to implement HPS, this work designs a sliding mode control (SMC) for synchronizing the state trajectories of two horizontal platform systems, subsequently allowing us to easily understand the HPS, perform more detailed analysis, and achieve further control. Experimental results demonstrate the feasibility of implementing the HPS by the proposed electronic circuit system. Comparing the proposed electronic circuitry designs and the HPS of computer simulation reveals that the results of the non-linear dynamic behavior correlate well with each other. Finally, based on use of the control technology, master-slave chaos synchronization with sliding mode control is achieved by wireless sensors.
\end{abstract}

\section{Introduction}

Chaos phenomenon is a complex dynamic behavior, owing to related characteristics such as sensitivity under initial conditions and a broad Fourier power spectrum. Chaotic systems have received considerable attention in recent years, especially with respect to the importance of the chaotic system in controlling the chaos phenomenon. Ott et al. developed a scheme to control chaotic systems for the first time in 1989, referred to as the O.G.Y method [1]. Recently, many control technologies were also used to implement two identical chaotic systems to achieve synchronization, such as adaptive control, feedback control, sliding mode control and fuzzy sliding mode control [2]. However, elucidating or controlling the non-linear behavior of mechanical systems is extremely difficult, necessitating the use of electronic components to replace mechanical systems produced by nonlinear behavior $[3,4]$.

Ge et al. [5] conducted linear feedback for HPS of a master-slave system in 2003. Following numerical verification, the initial value of the two different chaotic systems could be synchronized by the state errors of feedback controlling. Wu et al. [6] examined the feasibility of using robust control design to inhibit the chaos phenomenon.

Using electronic components is an efficient and costsaving approach to replace a mechanical system. In addition to developing an electronic circuit to implement HPS, this work designs a sliding mode control (SMC) for synchronizing the state trajectories of two horizontal platform systems. A switching surface, in that stability of the error dynamics in a sliding mode is guaranteed, is first proposed. Based on this switching surface, an SMC is derived not only to guarantee the sliding motion but also to avoid chattering, even when the system is undergoing uncertainties and external disturbances.

\section{Electronic Circuit Implementation of HPS}

Figure 1 describes the non-linear structure of HPS [7]. Within this system, the penetration of mass center can be rotated around the horizontal axis. An accelerometer is placed on the left side of the platform. When the platform goes off 


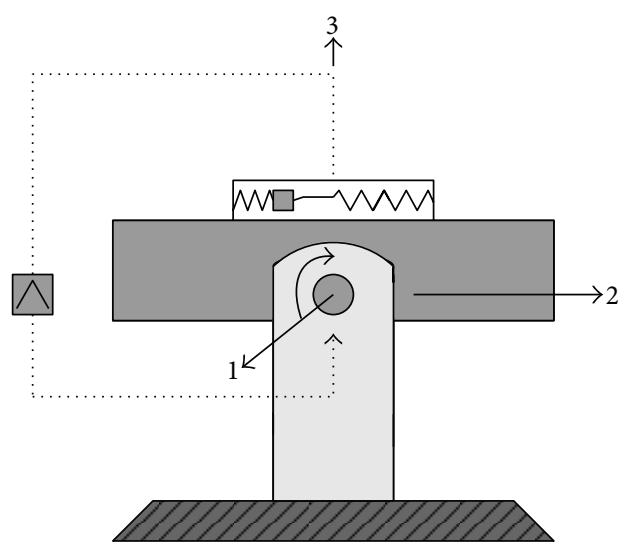

FIGURE 1: Horizontal platform system.

the horizon, the platform drives the accelerometer via an output signal to maintain balance. The dynamic equation of HPS is described as follows [7]:

$$
\begin{aligned}
A \ddot{x}(t) & +D \dot{x}(t)+r g \sin x(t) \\
& -\frac{3 g}{R}(B-C) \cos x(t) \cdot \sin x(t)=F \cos \omega t,
\end{aligned}
$$

where $A, B$ and $C$ denote the moment of inertia with the rotating axis in this platform; $D$ represents the damping coefficient; $R$ is radius of the earth; $r$ denotes the accelerometer of proportionality constant; $g$ denotes the gravitational constant; $x$ represents the rotation of a platform relative to the angle of the earth; $F \cos \omega t$ denotes the harmonic torque; $x_{1}(t)=x(t)$ and $x_{2}(t)=\dot{x}(t)$ are state variables in the system. The system is simplified by rewriting the system parameters as $a=D, r g=b, l=(3 g / R)(B-C)$, and $F=h$. Based on the above parameters, the state equation of HPS is rewritten as follows:

$$
\begin{aligned}
& \dot{x}_{1}=x_{2}, \\
& \dot{x}_{2}=-a x_{2}-b \sin x_{1}+l \cos x_{1} \cdot \sin x_{1}+h \cos \omega t .
\end{aligned}
$$

Parameter values of the system are $a=4 / 3, b=3.776$, $l=4.6 \times 10^{-6}, h=34 / 3$, and $\omega=1.8$; the initial value set is $\left(x_{1}(0), x_{2}(0)\right)=(1,-1)$. Figure 2 shows the results of time response of system (2) based on numerical simulation. According to Figure 2, the HPS has two state responses that are, very complex and irregular; in addition, the phase plane displays a strange attractor. Given the difficulty in implementing the mechanical system, this work designs a simple OP circuit to implement the HPS, as shown in Figure 3. Figure 4 illustrates the hardware system. Figure 5 displays the complex time responses of the hardware system for HPS.

\section{Chaos Synchronization Controller Design}

Owing to that some external disturbances occur in an actual system, this work considers the two factors that lack ability

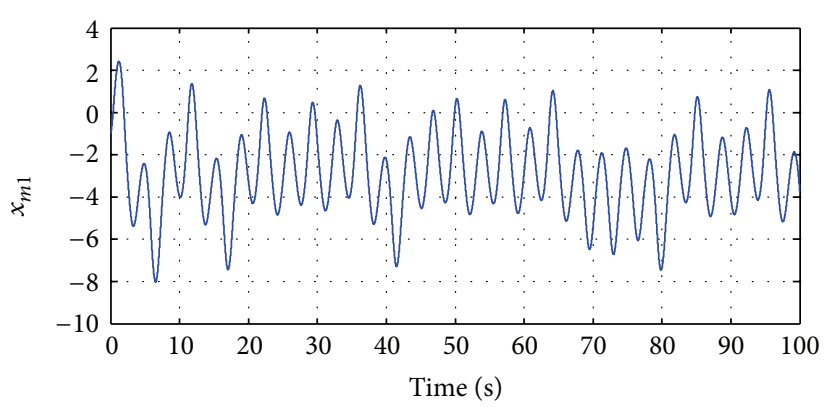

(a)

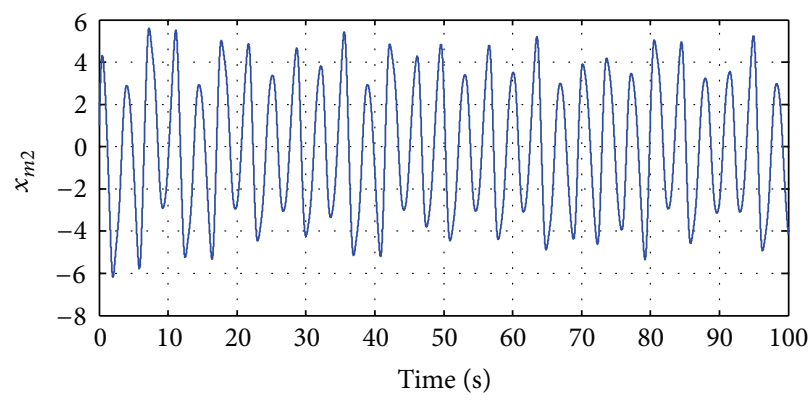

(b)

Figure 2: Numerical time responses of the HPS: (a) $x_{1}$ and (b) $x_{2}$.

and simplify the calculation. The HPS equation of masterslave is described as follows $[8,9]$.

Master system:

$$
\begin{aligned}
& \dot{x}_{m 1}=x_{m 2}, \\
& \dot{x}_{m 2}=-a x_{m 2}-b \sin x_{m 1}+l \cos x_{m 1} \cdot \sin x_{m 1}+h \cos \omega t .
\end{aligned}
$$

Slave system:

$$
\begin{aligned}
\dot{x}_{s 1}= & x_{s 2}, \\
\dot{x}_{s 2}= & -a x_{s 2}-b \sin x_{s 1}+l \cos x_{s 1} \cdot \sin x_{s 1} \\
& +h \cos \omega t+u+\Delta \xi+d(t) .
\end{aligned}
$$

The system parameters are $a=4 / 3 ; b=3.776, l=$ $4.6 \times 10^{-6} ; h=34 / 3 ; \omega=1.8 ; d(t)=0.1 \cos (t) ; \Delta \xi=$ $0.1 \sin (t) ; u$ denotes an input of the controller; $\Delta \xi$ denotes an uncertainty parameter of the system; and $d(t)$ denotes the external disturbance. Synchronization objectives are as follows:

$$
\lim _{t \rightarrow \infty}\left\|x_{s}(t)-x_{m}(t)\right\|=0
$$

Equations (3) and (4) are used to define the errors of the master-slave system:

$$
\begin{aligned}
& e_{1}=x_{s 1}-x_{m 1}, \\
& e_{2}=x_{s 2}-x_{m 2} .
\end{aligned}
$$




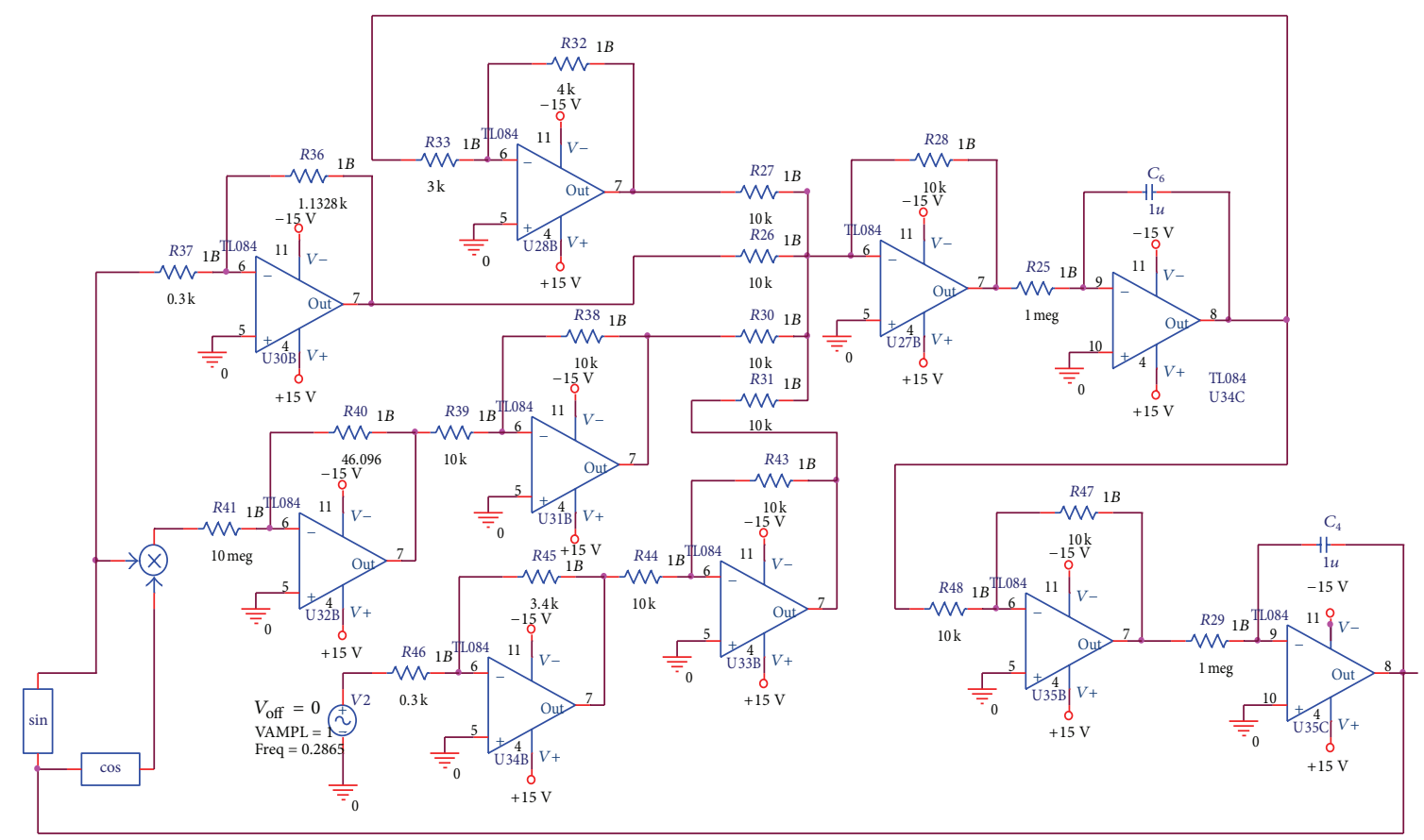

FIGURE 3: Electronic circuit design of HPS.

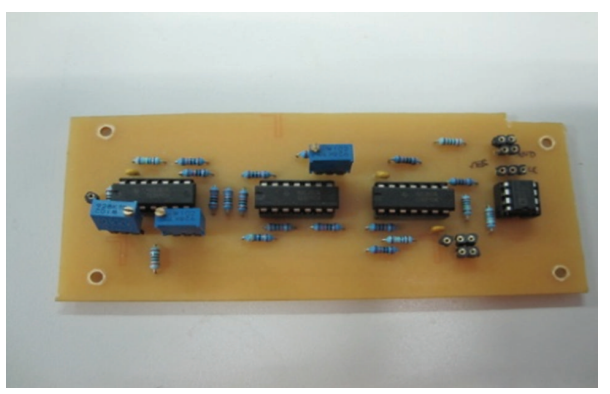

FIgURE 4: Hardware System of HPS.

Based on (6), the errors dynamic equation can be obtained as follows:

$$
\begin{aligned}
\dot{e}_{1}= & \dot{x}_{s 1}-\dot{x}_{m 1}=x_{s 2}-x_{m 2}=e_{2}, \\
\dot{e}_{2}= & \dot{x}_{s 2}-\dot{x}_{m 2} \\
= & -a\left(x_{s 2}\right)-b \sin \left(x_{s 1}\right)+l \cos \left(x_{s 1}\right) \cdot \sin \left(x_{s 1}\right) \\
& +h \cos \omega t+\Delta \xi+d(t)+u \\
& \quad-\left[-a\left(x_{m 2}\right)-b \sin \left(x_{m 1}\right)\right. \\
& \left.\quad+l \cos \left(x_{m 1}\right) \cdot \sin \left(x_{m 1}\right)+h \cos \omega t\right] \\
= & -a\left(e_{2}\right)-b\left[\sin \left(x_{s 1}\right)-\sin \left(x_{m 1}\right)\right] \\
& +l\left[\cos \left(x_{s 1}\right) \cdot \sin \left(x_{s 1}\right)\right. \\
& \left.\quad-\cos \left(x_{m 1}\right) \cdot \sin \left(x_{m 1}\right)\right] \\
& +\Delta \xi+d(t)+u(t) .
\end{aligned}
$$

Controller input $(u)$ is assumed to be the following equation:

$$
u=u_{\mathrm{eq}}+u_{\mathrm{sw}} \text {. }
$$

The sliding surface is defined as follows:

$$
s=c_{1} e_{1}+e_{2}
$$

When the closed-loop system under the sliding surface is $\dot{s}=$ 0

$$
\begin{aligned}
\dot{s}=c_{1} \dot{e}_{1} & +\dot{e}_{2} \\
\Longrightarrow & c_{1} e_{2}-a\left(e_{2}\right)-b\left[\sin \left(x_{s 1}\right)-\sin \left(x_{m 1}\right)\right] \\
& +l\left[\cos \left(x_{s 1}\right) \cdot \sin \left(x_{s 1}\right)-\cos \left(x_{m 1}\right) \cdot \sin \left(x_{m 1}\right)\right] \\
& +\Delta \xi+d(t)+u_{\mathrm{eq}}=0 .
\end{aligned}
$$




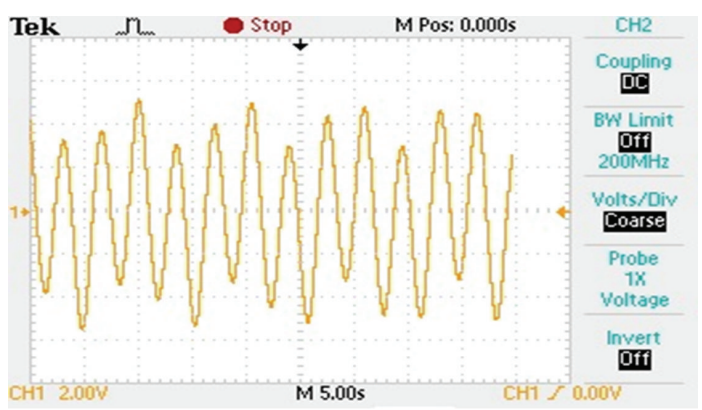

(a)

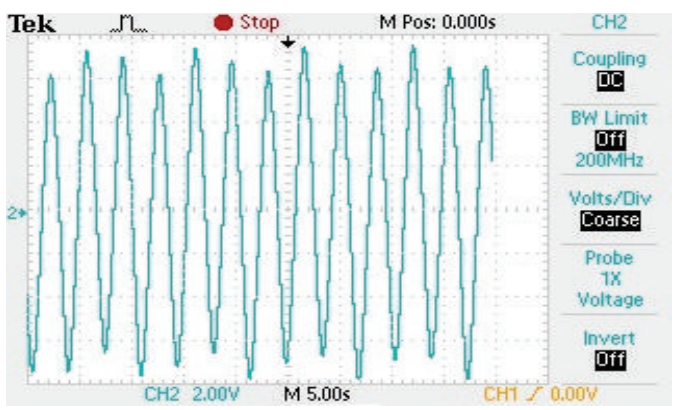

(b)

FIGURE 5: Chaotic dynamics of HPS in oscilloscope: (a) time response of $x_{1}$; (b) time response of $x_{2}$.

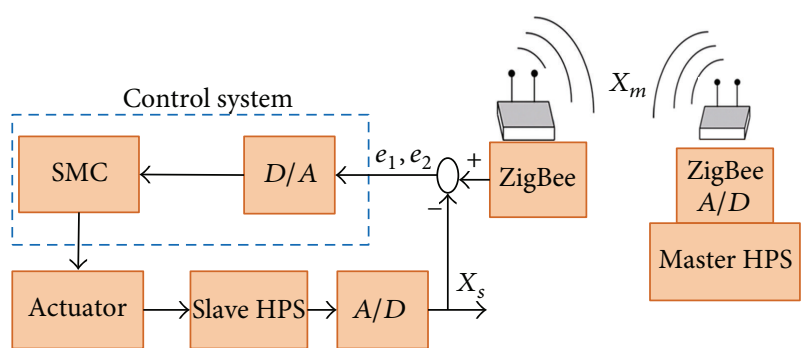

Figure 6: Experiment configuration.

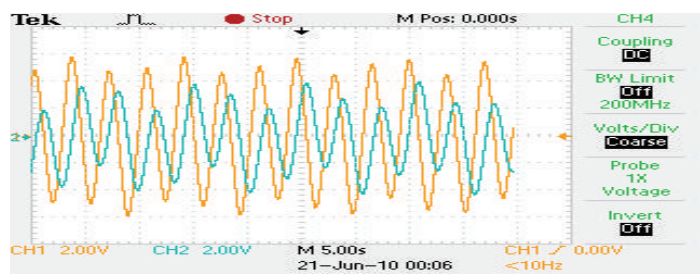

(a)

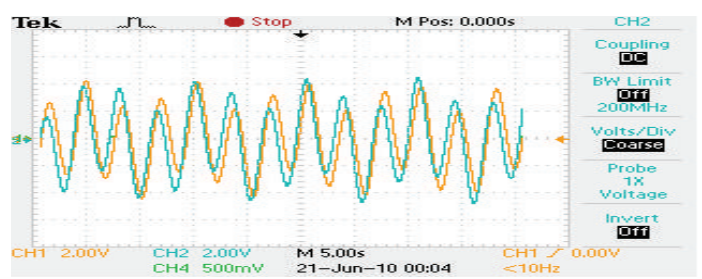

(b)

FIGURE 7: Uncontrolled time response of master-slave HPS in oscilloscope: (a) $x_{m 1}, x_{s 1}$; (b) $x_{m 2}, x_{s 2}$.

The equivalent control $\left(u_{\mathrm{eq}}\right)$ is obtained as follows:

$$
\begin{aligned}
u_{\mathrm{eq}}= & -c_{1} e_{2}+a\left(e_{2}\right)+b\left[\sin \left(x_{s 1}\right)-\sin \left(x_{m 1}\right)\right] \\
& -l\left[\cos \left(x_{s 1}\right) \cdot \sin \left(x_{s 1}\right)-\cos \left(x_{m 1}\right) \cdot \sin \left(x_{m 1}\right)\right] \\
& -\Delta \xi-d(t) .
\end{aligned}
$$

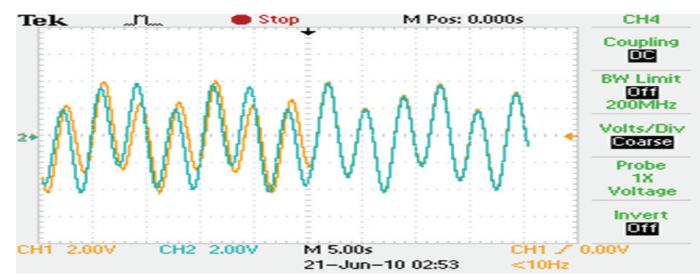

(a)

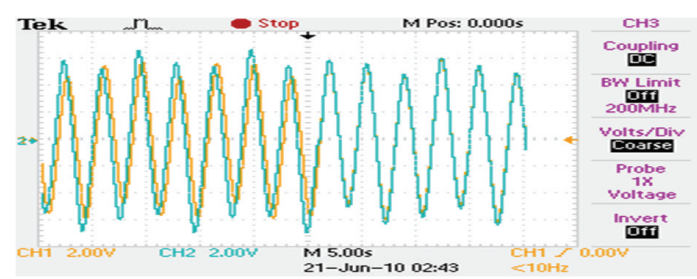

(b)

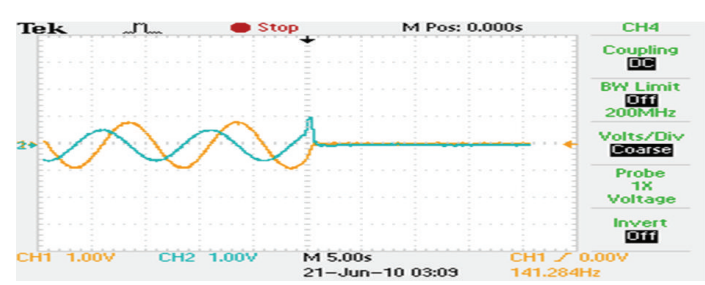

(c)

FIGURE 8: Time synchronization of hardware implementation of chaos synchronization in oscilloscope: (a) state response of $x_{m 1}, x_{s 1}$ (b) state response of $x_{m 2}, x_{s 2}$ and (c) state errors of $e_{1}, e_{2}$.

Owing to that the uncertainty parameter $(\Delta \xi)$ and external disturbances $(d(t))$ cannot be known, the real system controller can achieve the following:

$$
\begin{aligned}
u_{\mathrm{eq}}= & -c_{1} e_{2}+a\left(e_{2}\right)+b\left[\sin \left(x_{s 1}\right)-\sin \left(x_{m 1}\right)\right] \\
& -l\left[\cos \left(x_{s 1}\right) \cdot \sin \left(x_{s 1}\right)-\cos \left(x_{m 1}\right) \cdot \sin \left(x_{m 1}\right)\right] .
\end{aligned}
$$

The law of approaching control is designed as follows:

$$
u_{\mathrm{sw}}=-W \cdot \operatorname{sign}(s) \text {. }
$$




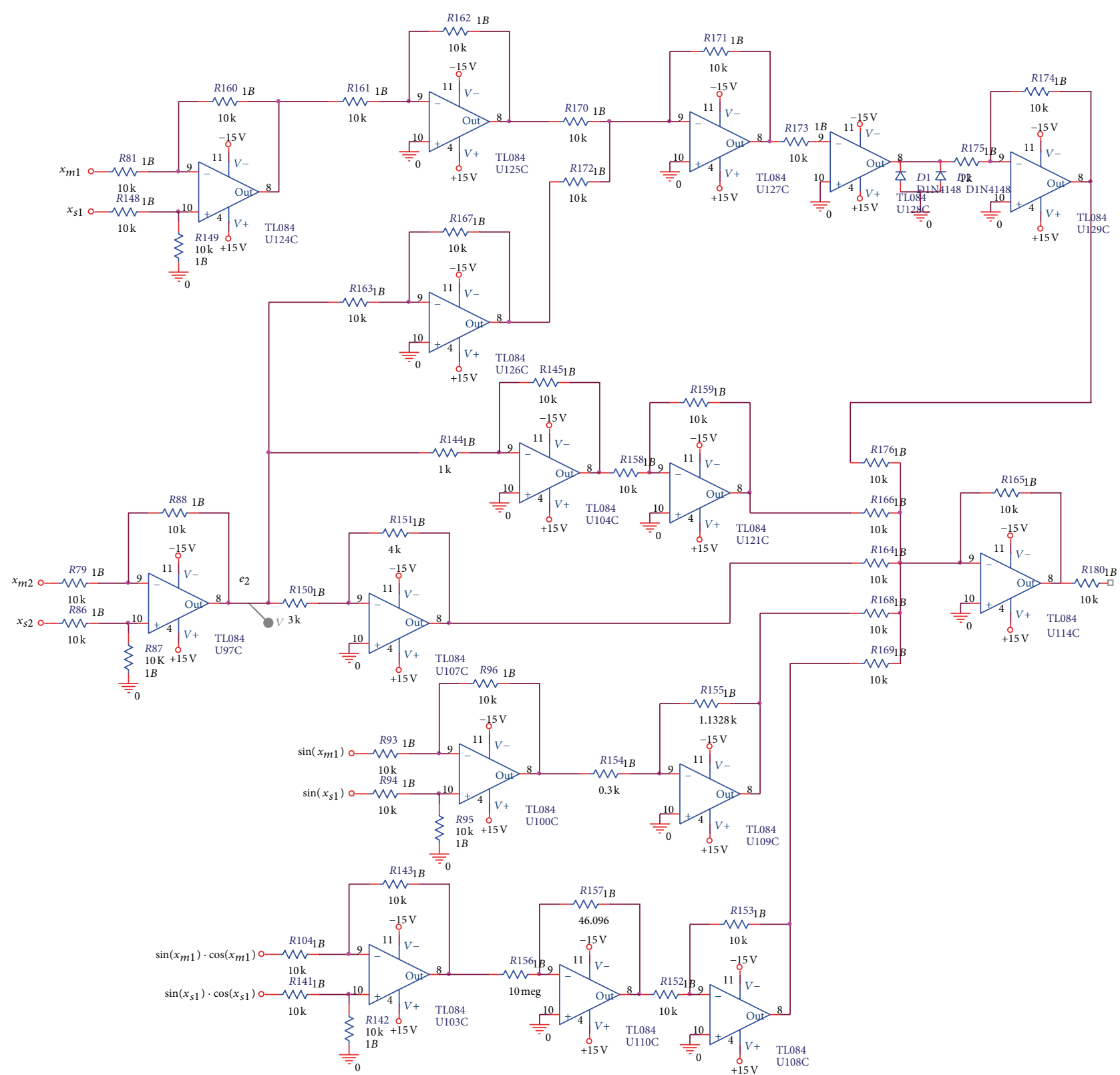

FIgURE 9: Circuit design of the sliding mode controller.

The $\operatorname{sign}(\cdot)$ function is defined as follows:

$$
\operatorname{sign}(s)= \begin{cases}1, & s>0, \\ 0, & s=0, \\ -1, & s<0 .\end{cases}
$$

The synchronization controller of HPS is described as follows:

$$
\begin{aligned}
u= & u_{\mathrm{eq}}+u_{\mathrm{sw}} \\
= & -c_{1} e_{2}+a\left(e_{2}\right)+b\left[\sin \left(x_{s 1}\right)-\sin \left(x_{m 1}\right)\right] \\
& -l\left[\cos \left(x_{s 1}\right) \cdot \sin \left(x_{s 1}\right)-\cos \left(x_{m 1}\right) \cdot \sin \left(x_{m 1}\right)\right] \\
& -W \cdot \operatorname{sign}(s) .
\end{aligned}
$$

Remark. The controllers in (15) demonstrate discontinuous control laws and the phenomenon of chattering will appear. In order to eliminate the chattering, the controller is modified as

$$
\begin{aligned}
u= & -c_{1} e_{2}+a\left(e_{2}\right)+b\left[\sin \left(x_{s 1}\right)-\sin \left(x_{m 1}\right)\right] \\
& -l\left[\cos \left(x_{s 1}\right) \cdot \sin \left(x_{s 1}\right)-\cos \left(x_{m 1}\right) \cdot \sin \left(x_{m 1}\right)\right] \\
& -W \cdot \frac{s}{|s|+\delta},
\end{aligned}
$$

where $\delta$ is a sufficiently small design constant. In this paper, the constant $\delta$ is selected as 0.05 . Therefore, the controllers can be implemented in real physical systems. 
Proof of Stability. Lyapunov function $V(t)$ is described as follows:

$$
V(t)=\frac{1}{2} s^{2}
$$

By substituting (15) into (17), the first derivative can be obtained as follows:

$$
\begin{aligned}
& \dot{V}= s \dot{s}=s\left[c_{1} e_{2}+\dot{e}_{2}\right] \\
&=s\left\{c_{1} e_{2}-a\left(e_{2}\right)-b\left[\sin \left(x_{s 1}\right)-\sin \left(x_{m 1}\right)\right]\right. \\
& \quad+l\left[\cos \left(x_{s 1}\right) \sin \left(x_{s 1}\right)-\cos \left(x_{m 1}\right) \sin \left(x_{m 1}\right)\right] \\
&\left.\quad+\Delta \xi+d(t)+u_{\mathrm{eq}}-W \cdot \operatorname{sign}(s)\right\} \\
&=s[\Delta \xi+d(t)-W \cdot \operatorname{sign}(s)] \\
&=s[\Delta \xi+d(t)]-W \cdot|s| .
\end{aligned}
$$

If $\Delta \xi$ and $d(t)$ are bounded, and $|\Delta \xi| \leq \gamma,|d(t)| \leq \delta$

$$
\begin{aligned}
\dot{V} & \leq s[\Delta \xi+d(t)]-W \cdot|s| \\
& \leq|s| \cdot[|\Delta \xi|+|d(t)|]-W \cdot|s| \\
& \leq|s| \cdot(\gamma+\delta-W) .
\end{aligned}
$$

If $W>(\gamma+\delta), \dot{V}<0$ can guarantee the stability of the system.

\section{Experiment Results}

Equations (3), (4), and (19) are used to perform the chaos synchronization of HPS and evaluate hardware implementation. The wireless sensor devices are used to send and receive the master and slave chaotic HPS signals. Experiment configuration is shown in Figure 6. The values $c_{1}=10$ and $W=10$ are used in controller implementation. First the master-slave system is inconsistent before adding the sliding mode controller in Figure 7. Additionally, two tracks of the system achieve synchronization after the control is active. Figure 8 shows time synchronization of hardware implementation. Given the inability of hardware to accurately specify time for adding to a controller, the middle point of time axis is used as the standard. Figure 9 shows the circuit design of the sliding mode controller.

\section{Conclusions}

This study elucidates the chaos behavior of HPS by an electronic circuit, which is divided into master-slave chaos systems. Given different initial values in the master-slave system, the master-slave chaos HPS can achieve synchronization through the action of the controller. Because the system and controller production process often contain a wide variety of external disturbances in part, a portion of the controller design must become robust to interference. Therefore, in terms of choosing the part of controller, this study uses a sliding mode control, thus ensuring that the masterslave HPS under the controller achieves synchronization by analogical sensors.

\section{References}

[1] E. Ott, C. Grebogi, and J. A. Yorke, "Controlling chaos," Physical Review Letters, vol. 64, no. 11, pp. 1196-1199, 1990.

[2] H.-T. Yau, "Design of adaptive sliding mode controller for chaos synchronization with uncertainties," Chaos, Solitons and Fractals, vol. 22, no. 2, pp. 341-347, 2004.

[3] M. Itoh, "Synthesis of electronic circuits for simulating nonlinear dynamics," International Journal of Bifurcation and Chaos in Applied Sciences and Engineering, vol. 11, no. 3, pp. 605-653, 2001.

[4] S. C. Tsay, C. K. Huang, D. L. Qiu, and W. T. Chen, "Implementation of bidirectional chaotic communication systems based on Lorenz circuits," Chaos, Solitons and Fractals, vol. 20, no. 3, pp. 567-579, 2004.

[5] Z. M. Ge, T. C. Yu, and Y. S. Chen, "Chaos synchronization of a horizontal platform system," Journal of Sound and Vibration, vol. 268, no. 4, pp. 731-749, 2003.

[6] X. Wu, J. Cai, and M. Wang, "Master-slave chaos synchronization criteria for the horizontal platform systems via linear state error feedback control," Journal of Sound and Vibration, vol. 295, no. 1-2, pp. 378-387, 2006.

[7] N.-S. Pai and H.-T. Yau, "Generalized projective synchronization for the horizontal platform systems via an integral-type sliding mode control," Journal of Vibration and Control, vol. 17, no. 1, pp. 11-17, 2011.

[8] N. S. Pai and S. P. Chang, "Design and implementation of fuzzy sliding mode controllers for generalized projective synchronization of chaos horizontal platform systems," Computers and Mathematics with Applications, vol. 64, no. 5, pp. 709-720, 2012.

[9] N.-S. Pai and H.-T. Yau, "Suppression of chaotic behavior in horizontal platform systems based on an adaptive sliding mode control scheme," Communications in Nonlinear Science and Numerical Simulation, vol. 16, no. 1, pp. 133-143, 2011. 


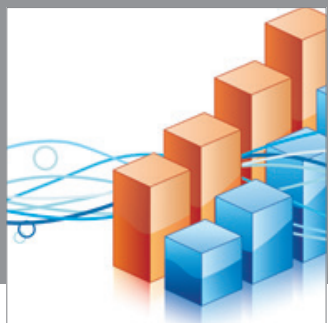

Advances in

Operations Research

mansans

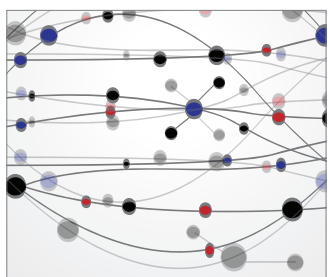

The Scientific World Journal
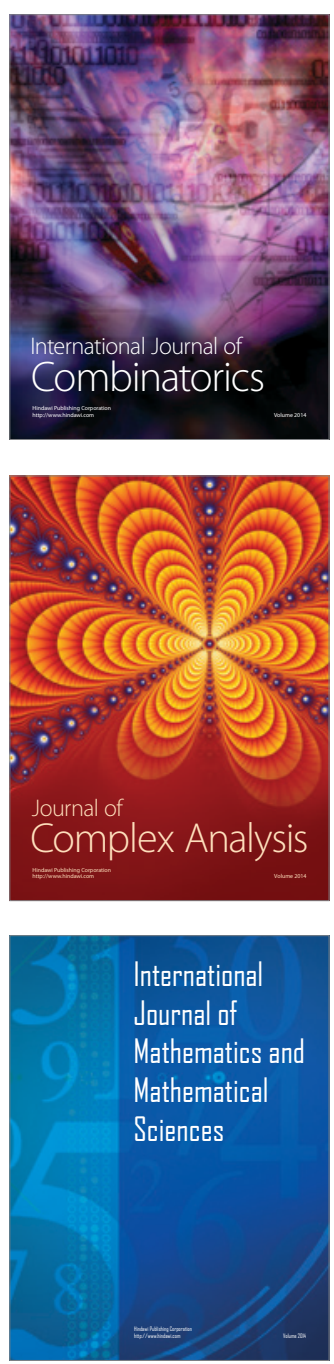
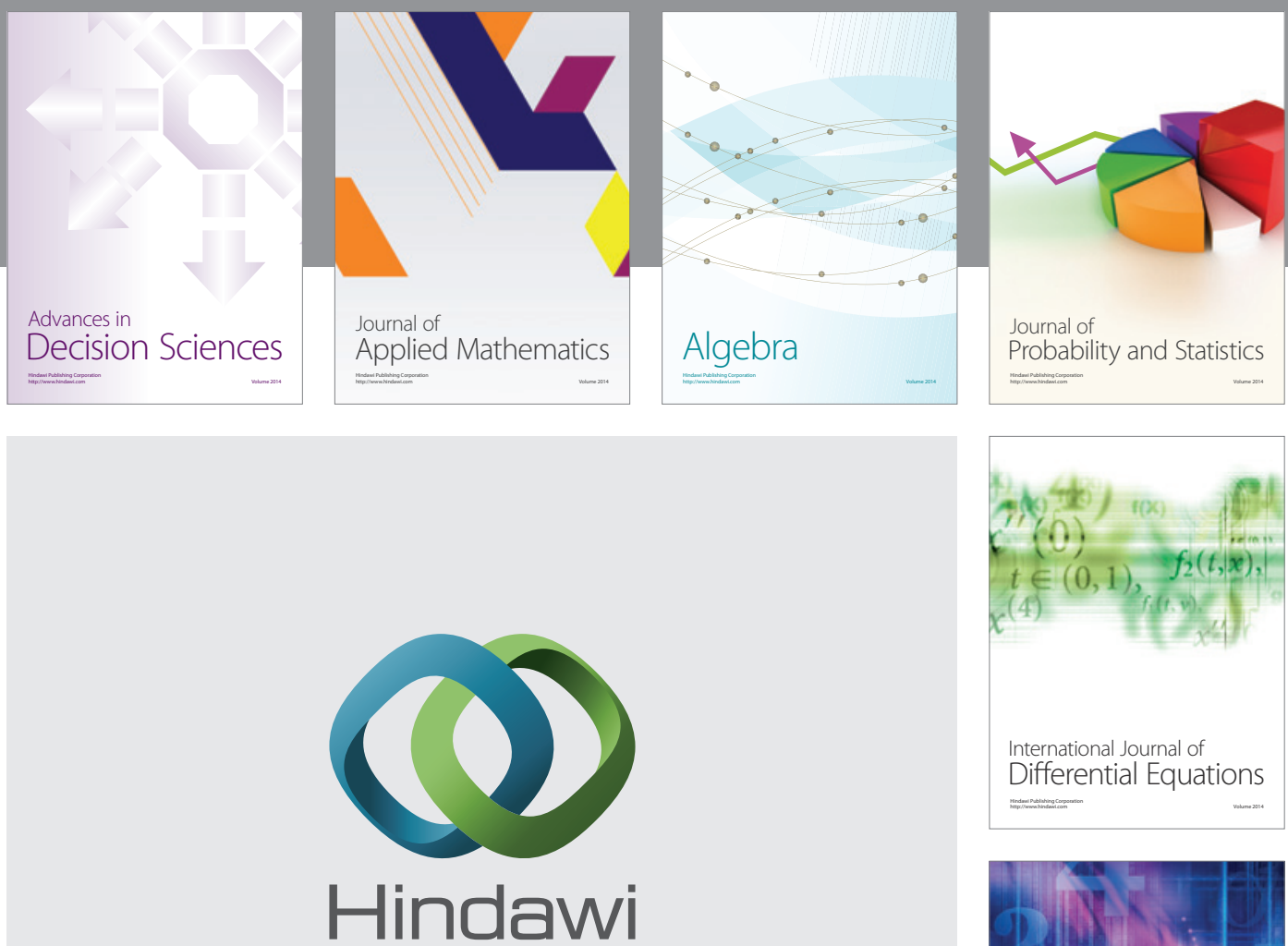

Submit your manuscripts at http://www.hindawi.com
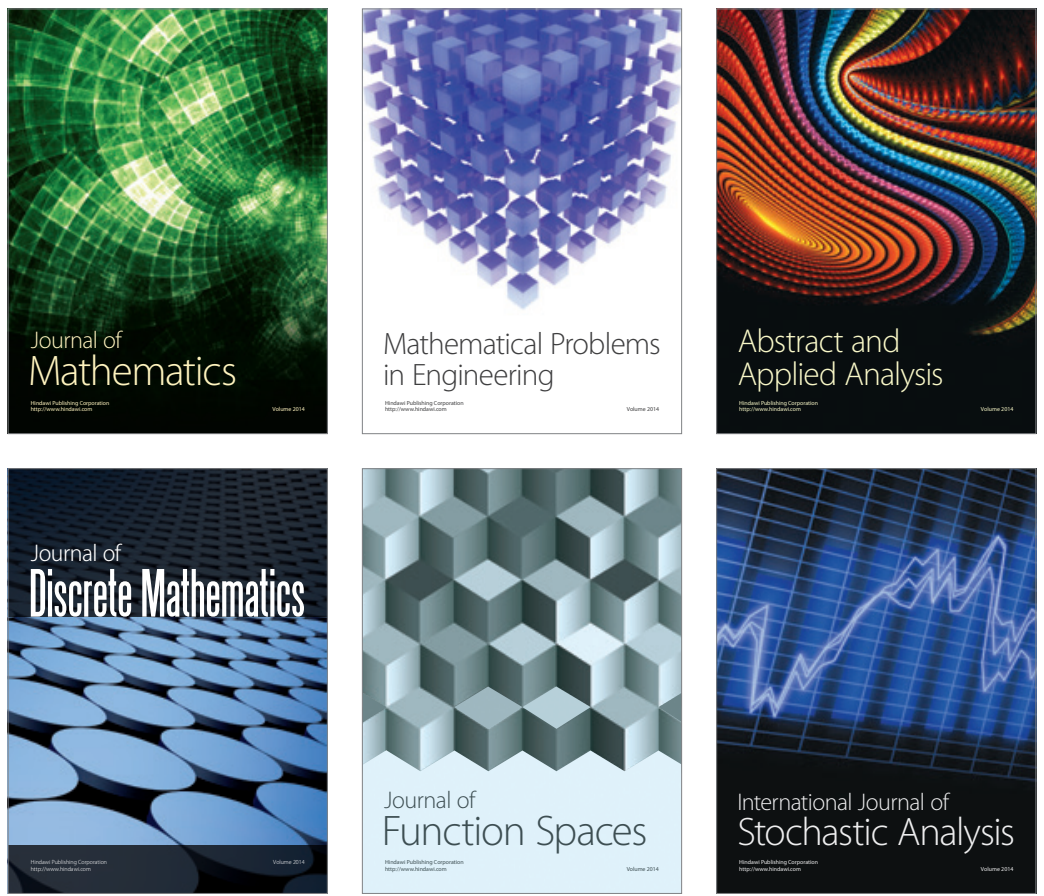

Journal of

Function Spaces

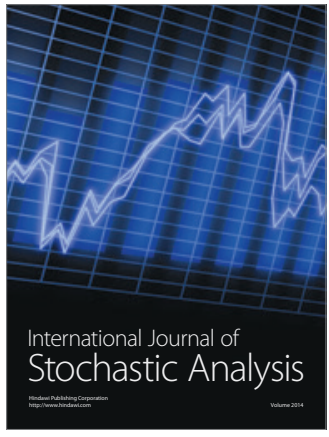

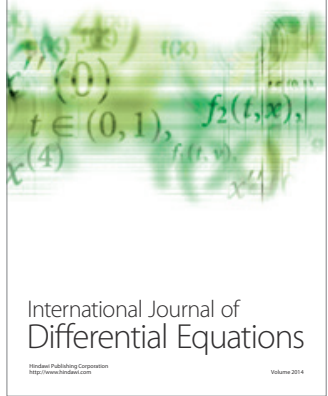
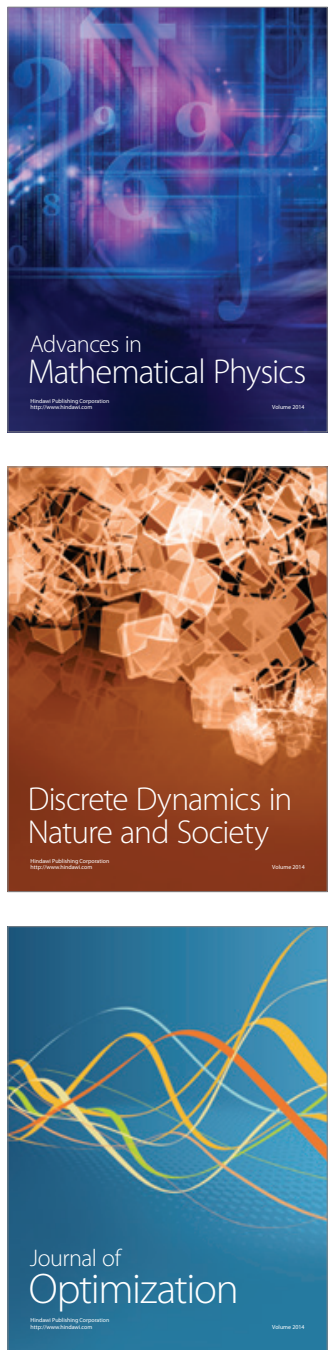